European Federation of Societies for Ultrasound in Medicine and Biology

\section{EFSUMB Membership}

Whether you are based in Europe or not, EFSUMB is now allowing members from across the world. Join a network of 31 countries and hundreds of individual members to support the continuous education for competence to practice ultrasound safely.

\section{EFSUMB MEMBER COUNTRIES}

The following National Societies are part of EFSUMB. If you live in these countries please register as part of your National Society which includes membership of EFSUMB and WFUMB: Albania, Austria, Belgium, Bulgaria, Croatia, Czech Republic, Denmark, France, Georgia, Germany, Greece, Hungary, Israel, Italy, Latvia, Lithuania, Moldova, The Netherlands, Norway, Poland, Portugal, Romania, Russia, Slovakia, Slovenia, Spain, Sweden, Turkey, Ukraine and United Kingdom.

\section{Advantages of EFSUMB include:}

- A Europe wide Ultrasound Federation which encourages networking between ultrasound professionals of all disciplines throughout Europe, allowing them to benefit from the wealth of experience and knowledge from other countries and other health-care systems.

- The annual EUROSON meetings which provide a unique opportunity to meet with practitioners from other European countries, to hear talks given by many international experts, to present exciting new data to colleagues from across Europe, and to become involved in ultrasound science, education, research, teaching and politics at a supranational level.

- The ability to influence Ultrasound issues on a worldwide basis through our membership of the World Federation for Ultrasound in Medicine and Biology.

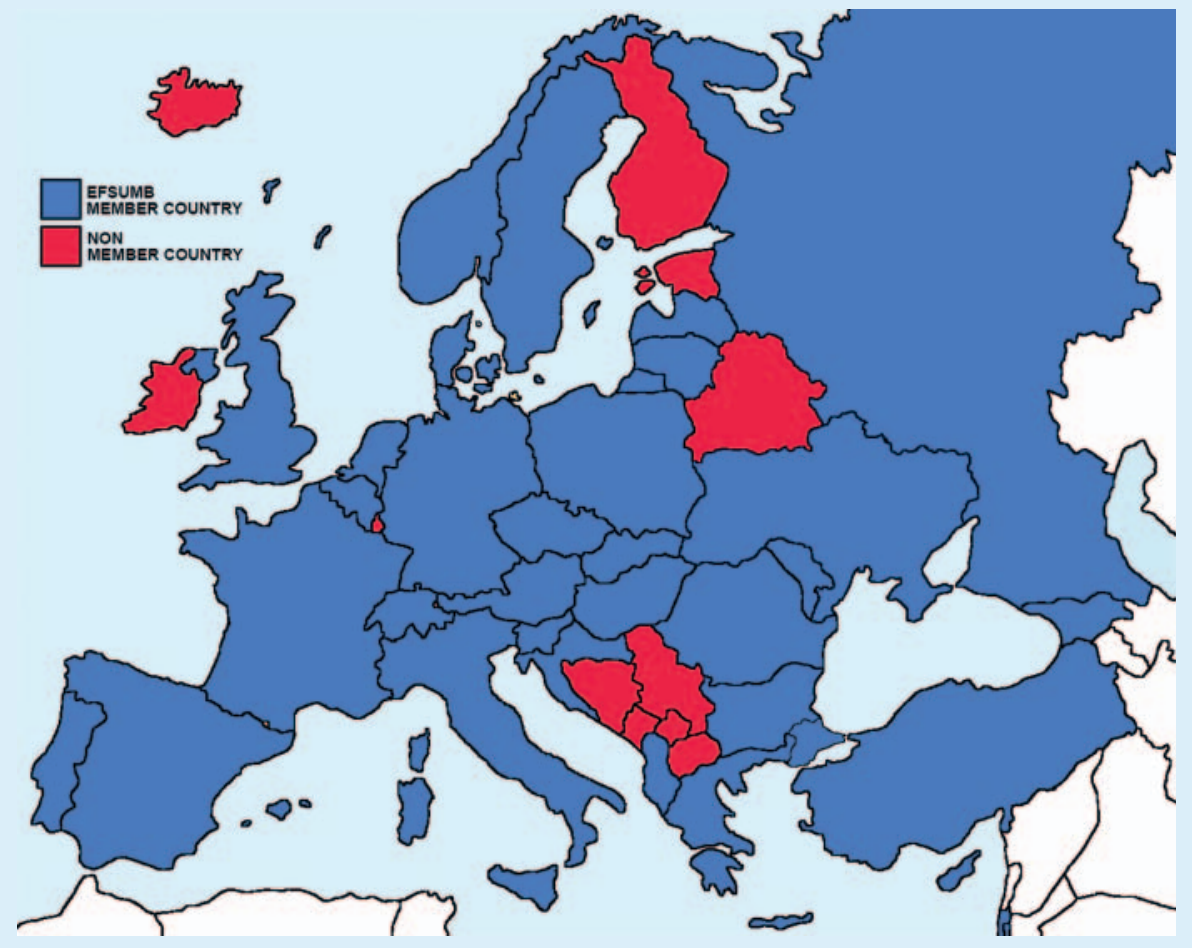

- Euroson schools which provide high-level ultrasound education in diverse parts of Europe.

- ECMUS - the EFSUMB Committee for Medical Ultrasound Safety, which takes a lead in keeping the membership upto-date with all aspects of medical ultrasound safety, and provides expert considered views through the publication of statements on ultrasound safety.

- The Education and Professional Development Committee which considers all aspects of medical ultrasound education and professional development throughout Europe, and publishes recommendations on a variety of matters such as minimum standards of training.

- The Publication Committee which ensures that the membership is kept up-to-date with the affairs of EFSUMB.
Advantages to individual members include:

- Participation in a large Pan-European ultrasound community.

- Eligibility to attend meetings of the EFSUMB General Assembly and comment on EFSUMB administration.

- Eligibility to serve on all EFSUMB committees as a co-opted member.

- Full access to the EFSUMB website.

- Opportunity to influence European and worldwide ultrasound issues through membership of EFSUMB.

- Reduced fees at EUROSON meetings.

- Reduced fees at many EFSUMB sponsored meetings.

- Reduced subscriptions to Ultraschall in der Medizine/European Journal of Ultrasound.

- Six Newsletters per year. 
- Automatic membership of the World Federation for Ultrasound in Medicine and Biology.

- Reduced subscriptions to Ultrasound in Medicine and Biology.

- Personalised membership certificates.

Join EFSUMB now by visiting www. efsumb.org and become a member as part of your own country's society or as an individual member

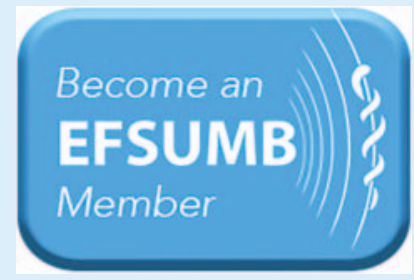

\section{INDIVIDUAL MEMBERS}

Individuals worldwide are invited to join EFSUMB including those European countries listed below for an annual fee of 25 euro per annum (or 100 euro for 5 years). Those individuals who are in low-income economies (according to the World Bank) are invited to membership at 10 euro.

\section{YEAR EFSUMB MEMBERSHIP}

\section{EURO}

(Belarus, Bosnia and Herzegovina, Estonia, Finland, Iceland, Ireland, Kosovo, Luxembourg, Montenegro, North Macedonia, Serbia \& Rest of the World).

\section{YEARS EFSUMB MEMBERSHIP}

\section{EURO}

(Belarus, Bosnia and Herzegovina, Estonia, Finland, Iceland, Ireland, Kosovo, Luxembourg, Montenegro, North Macedonia, Serbia \& Rest of the World).

\section{LOW INCOME COUNTRIES}

\section{EURO}

(Afghanistan, Benin, Burkina Faso, Burundi, Central African Republic, Chad, Congo, Dem. Rep, Eritrea, Ethiopia, Gambia, Guinea, Guinea-Bissau, Haiti, Korea, Dem. People's Rep., Liberia, Madagascar, Malawi, Mali, Mozambique, Nepal, Niger, Rwanda, Sierra Leone, Somalia, South Sudan, Syrian Arab Republic, Tajikistan, Tanzania, Togo, Uganda, Yemen Rep.) 